\title{
The effect of ice ingestion during endurance exercise
}

\author{
Gaizka Mejuto*, Stephanie Gilbert, Sam Chalmers, Roger Eston, David Bentley \\ From 15th International Conference on Environmental Ergonomics (ICEE XV) \\ Portsmouth, UK. 28 June - 3 July 2015
}

\section{Introduction}

When exercising in a hot and humid environment, athletes encounter thermoregulatory strain leading to decreased central neurological drive and reduced skeletal muscle activation [1]. Reducing initial core temperature prior to exercise increases the capacity to store metabolic and environmental heat [2]. It has been also found that ice 'slurry' ingestion is an effective precooling strategy reducing rectal temperature $\left(\mathrm{T}_{\mathrm{re}}\right)$ [5]. The purpose of this study was to compare the effects of ice slurry ingestion before exercise in the heat with combined precooling (with ice slurry) and ingestion of ice slurry during exercise on endurance performance in hot conditions.

\section{Methods}

Eight well-trained, male cyclists (age $=33.7(9.2)$ yrs, $\mathrm{VO}_{2} \max =58.3(5.9)$ participated in the study. Participants were allocated an order of trials in a randomised crossover design. Trials were (1) no cooling before or during exercise (thermo-neutral, TN), (2) precooling and no cooling during exercise (precooling only, PO), or (3) precooling and cooling during exercise (precooling and cooling during, $\mathrm{PCD}$ ). The experimental trials took place in hot environmental conditions $\left(32{ }^{\circ} \mathrm{C}, 50 \%\right.$ relative humidity) in an environmental chamber. In these conditions participants exercised on a cycle ergometer at $70 \%$ $\mathrm{VO}_{2} \max (\mathrm{SS})$ for 45 mins, followed by a $10 \mathrm{~km}$ time trial (TT), using self-selected cadence and intensity. The effects of the different cooling strategies on each physiological variable were assessed using a two way ANOVA (trial $\times$ time). For all comparisons, significance was set at $\mathrm{p}=0.05$.

* Correspondence: gaizka.mejuto@ehu.es

Human Performance Laboratory, Department of Sport and Physical

Education, University of the Basque Country, Vitoria-Gasteiz, Spain

\section{Results}

There were no significant differences in performance between the conditions in the $10 \mathrm{~km}$ TT performance (TN: 14.90(0.99), PO: 15.2(1.14), PCD: 15.30(1.15) mins, $\mathrm{p}=$ 0.72 ) but $T_{\text {re }}$ was significantly lower in $P O$ and $P C D$ than TN during SS cycling $(\mathrm{p}<0.05)$ and in the TT $(\mathrm{p}<0.05)$.

\section{Discussion}

These findings contrast recent studies which report ice slurry ingestion to improve endurance performance in the heat [4]. A common variation in these studies from the present study is the duration of the exercise protocol. However, in the present study, ingested ice-slurry is an effective way in reducing $\mathrm{T}_{\mathrm{re}}$ as other studies have previously reported [3].

\section{Conclusion}

The ingestion of ice slurry may be a practical and effective way of cooling the body before and during exercise. This may be beneficial in reducing occurrences of heat stress. Additionally, this study showed that the cooling measures may only be beneficial to performance in longer duration exercise when an athlete is under high levels of heat stress.

Published: 14 September 2015

\section{References}

1. Noakes TD: Physiological models to understand exercise fatigue and the adaptations that predict or enhance athletic performance. Scandinavian Journal of Medicine and Science in Sports 2000, 10:123-145.

2. Ross M, Abbiss C, Laursen P, Martin D, Burke L: Precooling Methods and Their Effects on Athletic Performance: A Systematic Review and Practical Applications. Sports Med 2013, 43:207-225.

3. Burdon CA, Hoon MW, Johnson NA, Chapman PG, O'Connor HT: The effect of ice slushy ingestion and mouthwash on thermoregulation and endurance performance in the heat. Int J Sports Med 2013, 23(5):458-469.

4. Insan M, Landers G, Brearley M, Peeling P: Beneficial Effects of Ice Ingestion as a Precooling Strategy on 40-km Cycling Time-Trial 
Performance. International Journal of Sports Physiology and Performance 2010, 5:140-151.

5. Siegel R, Mat J, Watson G, Nosaka K, Laursen PB: Pre-cooling with ice slurry ingestion leads to similar run times to exhaustion in the heat as cold water immersion. Journal of Sports Sciences 2012, 30(2):155-165.

doi:10.1186/2046-7648-4-S1-A126

Cite this article as: Mejuto et al:: The effect of ice ingestion during endurance exercise. Extreme Physiology \& Medicine 2015 4(Suppl 1):A126.

Submit your next manuscript to BioMed Central and take full advantage of:

- Convenient online submission

- Thorough peer review

- No space constraints or color figure charges

- Immediate publication on acceptance

- Inclusion in PubMed, CAS, Scopus and Google Scholar

- Research which is freely available for redistribution

Submit your manuscript at www.biomedcentral.com/submit
() Biomed Central 